СОДЕРЖАНИЕ МОЧЕВОЙ КИСЛОТЫ, КОНЦЕНТРАЦИЯ РЕНИНА У ПАЦИЕНТОК С ПРЕЭКЛАМПСИЕЙ В ЗАВИСИМОСТИ ОТ УРОВНЯ ВИТАМИНА D И ОСОБЕННОСТИ ЭПИДУРАЛЬНОЙ АНАЛЬГЕЗИИ РОДОВ

\author{
Е. В. ОРЕШНИКОВ ${ }^{1,2}$, Э. Н. ВАСИЛЬЕВА ${ }^{1,2}$, Л. И. МАЛЬЦЕВА, Т. Г. ДЕНИСОВА \\ 'ГАУ ДПО «Институт усовершенствования врачей» Минздрава Чувашии, г. Чебоксары, РФ \\ ФГБОУ ВО «Чувашский государственный университет им. И. Н. Ульянова», г. Чебоксары, РФ \\ ЗЗазанская государственная медицинская академия - филиал ФГБОУ ДПО «Российская медицинская академия непрерывного \\ профессионального образования» МЗ РФ, г. Казань, РФ
}

Цель: изучение связи концентрации ренина и содержания мочевой кислоты у беременных с преэклампсией на фоне дефицита витамина D и влияния на течение беременности, исходов родов и состояние новорожденных.

Материал и методы. У беременных с преэклампсией и группы контроля изучены содержание мочевой кислоты, витамина D, эндотелина и концентрация ренина, использованы иммуноферментные и спектрофотометрический методы. Материал исследования - венозная кровь. Результаты. У пациенток с тяжелой преэклампсией на фоне дефицита витамина D $(11,23 \pm 1,60$ нг/мл) отмечены гиперурикемия (435,61 \pm 24,05 мкмоль/л), повышение концентрации ренина в крови в 10 раз. Дефицит витамина D связан с более высокой потребностью введения эпидурально местных анестетиков при анальгезии родов у пациенток с преэклампсией по сравнению с группой контроля и неблагоприятными перинатальными исходами.

Выводы. У пациенток с преэклампсией выявлены: низкий уровень витамина D, гиперурикемия, повышенная концентрация ренина в крови, что ассоциировано с выраженностью болевого синдрома и повышением артериального давления. Для адекватной анальгезии и контроля артериального давления в родах им необходима более высокая скорость введения местных анестетиков. Возможно, восполнение дефицита витамина во время беременности улучшит перинатальные исходы.

Ключевые слова: эпидуральная анальгезия, дефицит витамина D, преэклампсия, роды, гиперурикемия, концентрация ренина

Для цитирования: Орешников Е. В., Васильева Э. Н., Мальцева Л. И., Денисова Т. Г. Содержание мочевой кислоты, концентрация ренина у пациенток с преэклампсией в зависимости от уровня витамина D и особенности эпидуральной анальгезии родов // Вестник анестезиологии и реаниматологии. - 2019. - Т. 16, № 1. - C. 56-62. DOI: 10.21292/2078-5658-2019-16-1-56-62

\title{
URIC ACID CONTENT, RENIN CONCENTRATION IN PATIENTS WITH PRE-ECLAMPSIA, DEPENDING ON THE LEVEL OF VITAMIN D AND CHARACTERISTICS OF EPIDURAL ANALGESIA IN LABOR
}

\section{E. V. ORESHNIKOV ${ }^{1,2}$, E. N. VASILIEVA ${ }^{1,2}$, L. I. MALTSEVA ${ }^{3}$, T. G. DENISOVA ${ }^{1,2}$}

IInstitute of Continuing Medical Education, Cheboksary, Russia

${ }^{2}$ Chuvash State University named after I. N. Ulyanov, Cheboksary, Russia

${ }^{3}$ Kazan State Medical Academy - Branch of Russian Medical Academy of Continuing Professional Education, Kazan, Russia

The objective: to investigate the correlation of renin concentration and uric acid content in pregnant women with pre-eclampsia and vitamin D deficiency and their impact on the course of pregnancy, childbirth, and infant status.

Subjects and methods. The content of uric acid, vitamin D, endothelin and renin concentration were studied in pregnant women with pre-eclampsia and the control group; enzyme immunoassay and spectrophotometric tests were used. Venous blood was used as a specimen for tests.

Results. Hyperuricemia (435.61 $\pm 24.05 \mu \mathrm{mol} / \mathrm{l}$ ) and a 10-fold increase of renin concentration were observed in patients with severe pre-eclampsia and vitamin D deficiency $(11.23 \pm 1.60 \mathrm{ng} / \mathrm{ml})$. Vitamin D deficiency is associated with a higher need for epidural administration of local anesthetics during labor analgesia in patients with pre-eclampsia versus the control group; it is also associated with unfavorable perinatal outcomes.

Conclusions. The following was detected in the patients with pre-eclampsia: low levels of vitamin D, hyperuricemia, elevated blood renin concentration, which was associated with the severity of pain and increased blood pressure. For adequate analgesia and blood pressure control during labor, they needed a higher rate of local anesthetic administration. Perhaps, replenishing vitamin deficiencies during pregnancy may improve perinatal outcomes. Key words: epidural analgesia, vitamin D deficiency, pre-eclampsia, labor, hyperuricemia, renin concentration

For citations: Oreshnikov E.V., Vasilieva E.N., Maltseva L.I., Denisova T.G. Uric acid content, renin concentration in patients with pre-eclampsia, depending on the level of vitamin D and characteristics of epidural analgesia in labor. Messenger of Anesthesiology and Resuscitation, 2019, Vol. 16, no. 1, P. 56-62. (In Russ.) DOI: 10.21292/2078-5658-2019-16-1-56-62

Преэклампсия остается тяжелым осложнением течения беременности и родов, основной причиной материнской смертности и перинатальной заболеваемости и смертности $[3,5]$. Преэклампсия является причиной смертности почти 100 тыс. женщин в мире ежегодно. Неполноценная инвазия трофобласта и эндотелиальная дисфункция общепризнаны как ключевые факторы патогенеза преэклампсии.
С увеличением числа беременных с тяжелыми экстрагенитальными заболеваниями в России частота преэклампсии возросла до 22\% [1, 2, 8].

Доказана связь витамина D с развитием преэклампсии, так как рецепторы к витамину D выявлены в органах репродуктивной системы. Витамин $\mathrm{D}$ имеет стероидную структуру и легко проникает в клетку через цитоплазматическую мембрану, свя- 
зываясь с рецептором (VDR), который является членом надсемейства ядерных рецепторов [13-15]. Витамин D участвует в формировании плода, ингибирует клеточную пролиферацию, индуцирует клеточную дифференцировку, воздействует на ангиогенез и выработку ренина, стимулирует образование инсулина $[9,10]$.

Дефицит витамина D обусловливает неполноценную инвазию трофобласта и негативно влияет на процесс гестации, а повышение уровня мочевой кислоты отражает степень повреждения эндотелия.

По мнению зарубежных авторов, индикаторами преэклампсии, кроме гипертензии и протеинурии, является повышение уровня мочевой кислоты [12].

Во многих исследованиях доказана связь дефицита витамина D и гиперурикемии с преэклампсией и другими осложнениями течения беременности, рождением детей с синдромом задержки роста плода $[7,16]$. В диагностике преэклампсии, наряду с протеинурией, результативно исследование содержания мочевой кислоты в крови беременных [17, 18].

Цель исследования: изучение связи концентрации ренина и содержания мочевой кислоты у беременных с преэклампсией на фоне дефицита витамина $\mathrm{D}$ и влияния на течение беременности, исходов родов и состояние новорожденных.

\section{Материалы и методы}

В исследование включены три группы пациенток. Основная группа - 35 беременных с преэклампсией - разделена на 2 подгруппы: 1-я 12 пациенток, у которых диагностирована тяжелая преэклампсия; 2-я группа - 23 пациентки с умеренной преэклампсией. Диагноз формулировали в соответствии с Международной статистической классификацией болезней и проблем, связанных со здоровьем, X пересмотра (МКБ-10) и по критериям диагностики преэклампсии согласно клиническим рекомендациям «Гипертензивные расстройства во время беременности, в родах и послеродовом периоде. Преэклампсия. Эклампсия» [3]. Тридцать женщин с физиологически протекающей беременностью без соматических патологий составили 3 -ю группу - контрольную.

У пациенток, допущенных к родам через естественные родовые пути, выполняли эпидуральную анальгезию во всех группах.

У беременных с реализованной преэклампсией изучены содержание мочевой кислоты, витамина $\mathrm{D}$, эндотелина и концентрация ренина. Материалом исследования была венозная кровь, для определения обеспеченности витамина D и концентрации ренина использовали иммуноферментные методы: наборы фирмы BIOMEDICAGRUPPE (Германия) и ImmunoChem (США). Концентрацию мочевой кислоты определяли с помощью спектрофотометрического метода по J. H. Marimont, M. London.
Статистическую обработку полученных результатов проводили с использованием пакетов программы Statistica для Windows (версия 8.0).

Рассчитывали среднюю арифметическую и стандартную ошибку $(\mathrm{M} \pm \mathrm{m})$. С помощью критериев Стъюдента $(p)$ оценивали количественные различия, критерий Манна - Уитни $(p \mathrm{~m}-\mathrm{u})$ применяли при неправильном распределении сравниваемых показателей. Критерий хи-квадрат $\left(p_{\chi 2}\right)$ использовали при оценке различий между группами относительных величин. Точный метод Фишера $\left(p_{\mathrm{F}}\right)$ применяли при значениях менее 5.

\section{Результаты}

Возраст беременных колебался от 18 до 35 лет, большую часть (21) составили женщины 28-33 лет. Пациентки с развившейся преэклампсией отличались наличием большого количества экстрагенитальных заболеваний. Соматический анамнез был отягощен у 93\% пациенток. Преобладали сердечно-сосудистые заболевания, ожирение, заболевания почек, которые диагностированы у каждой третьей беременной с преэклампсией. Частыми патологиями были заболевания ЛОР-органов и органов дыхания, выявленные в анамнезе у 37,5\% беременных с преэклампсией. Патология щитовидной железы обнаружена у женщин с физиологическим течением беременности в 23,3\% случаев, у пациенток с тяжелой преэклампсией - в 53,4\%, с умеренной преэклампсией в 36,4\% случаев. Заболевания желудочно-кишечного тракта и печени в анамнезе беременных с преэклампсией фиксировали в 30,5\% случаев.

Анализ данных гинекологического анамнеза выявил высокий процент воспалительных заболеваний, эндометриоза у пациенток с развившейся преэклампсией, что способствовало неполноценной инвазии трофобласта и последующим осложнениям беременности. Отягощенный акушерский анамнез имели 18 беременных с преэклампсией (медицинские и самопроизвольные аборты - у 13, внематочная беременность - у 2, преждевременные роды - у 2, задержка внутриутробного развития плода - у 1). Беременность протекала с осложнениями у всех женщин с преэклампсией, начиная с ранних сроков: ранний токсикоз наблюдался у 8 (23,6\%), угроза прерывания беременности - у 16 (46,4\%) пациенток, у $11(31,4 \%)$ из них обнаруживалась ретрохориальная гематома. Плацентарная недостаточность установлена в 32 недели у $8(20,3 \%)$, многоводие - у 7 (20,3\%), гипо- или гиперплазия плаценты - у 13 (37,7\%) пациенток.

При сопоставлении среднего артериального давления (АД) до родоразрешения выявлены значимо более высокие цифры у пациенток с преэклампсией - 121,6 [115-135] мм рт. ст., чем у беременных группы сравнения $-84,5$ [79,3-92,2] мм рт. ст. $(p=0,008)$ (рис.).

Перед родами изучили уровни витамина $\mathrm{D}$, мочевой кислоты и концентрацию ренина в сыворотке крови у беременных групп исследования. 


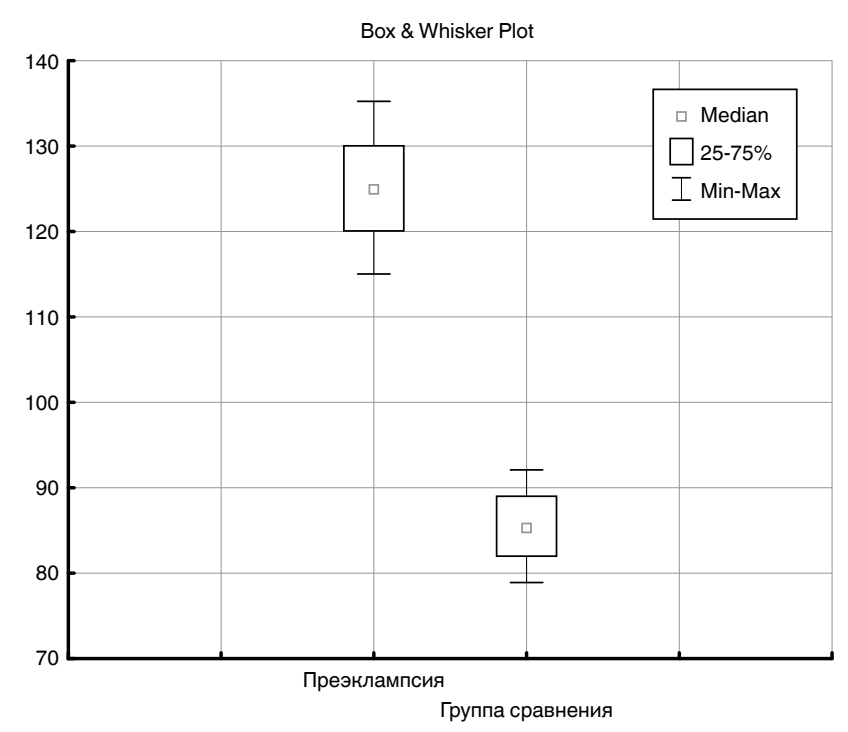

Рис. Распределение МАР в исследуемых группах

Fig. MAP distribution in the groups within the study

При тяжелой преэклампсии обнаружили: низкий уровень витамина $\mathrm{D}-11,23 \pm 1,60$ нг/мл, гиперурикемию - 435,61 $\pm 24,05$ мкмоль/л, повышенную концентрацию ренина $-61,4 \pm 0,6$ пг/мл; при преэклампсии средней степени тяжести уровень витамина $\mathrm{D}$ составил $13,16 \pm 1,40$ нг/мл, гиперурикемия была менее выражена - 315,52 \pm 17,05 мкмоль/л, концентрация ренина выше, чем в группе сравнения, $-41,4 \pm 0,4$ пг/мл. В группе сравнения уровень витамина D составил 31,2 $\pm 1,7$ нг/мл, концентрация мочевой кислоты $-267,00 \pm 32,25$ мкмоль/л, концентрация ренина $-5,1 \pm 0,3$ пг/мл.

Необходимо подчеркнуть, что у пациенток с преэклампсией на фоне дефицита витамина D отмечены гиперурикемия, повышение уровня эндотелина и концентрации ренина в крови. При этом отмечено двухкратное увеличение эндотелина по сравнению со здоровыми при умеренной преэклампсии и двадцатикратное - при тяжелых формах. При тяжелой преэклампсии концентрация ренина в плазме крови в 10 раз превышала концентрацию ренина у здоровых беременных, содержание мочевой кислоты соответствовало критериям «жесткой» гиперурикемии.

Получены статистически значимые корреляции между низкими значениями витамина D и повышенным АД ( $\mathrm{r}=0,68 ; p<0,01)$, повышенным содержанием мочевой кислоты $(\mathrm{r}=0,36 ; p<0,05)$, высоким уровнем эндотелина в крови $(\mathrm{r}=0,56 ; p<0,01)$, высокой концентрацией ренина $(\mathrm{r}=0,72 ; p<0,01)$, ранним началом преэклампсии $(\mathrm{r}=0,46 ; p<0,05)$.

Среди пациенток с преэклампсией к родам через естественные родовые пути допущены 18 (50,7\%) беременных на сроке 37-39 недель. Во время беременности прооперированы $4(11,4 \%)$ пациентки с тяжелой преэклампсией: 3 - в связи с нарастанием тяжести преэклампсии, 1 - с преждевременной отслойкой нормально расположенной плаценты.

Роды через естественные родовые пути велись с применением эпидуральной анальгезии. Роже- ницам с преэклампсией на фоне низкого уровня витамина $\mathrm{D}$, гиперурикемии и повышенным содержанием ренина и эндотелина в крови для адекватной анальгезии и контроля АД, как правило, необходимо большее количество местного анестетика в час, чем беременным с нормальным уровнем витамина D (табл. 1). У пациенток с тяжелой преэклампсией отмечено более высокое АД на фоне эпидуральной анальгезии: 140/90 - 150/100 мм рт. ст.; у пациенток с умеренной преэклампсией АД во время эпидуральной анальгезии составило 130/90 $125 / 85$ мм рт. ст. В группе сравнения АД в родах 105/60 - 120/70 мм рт. ст.

В родах возникли следующие осложнения: затяжное течение родов вследствие слабости родовых сил - 7 (20,3\%), дискоординация родовой деятельности - 1 (2,9\%), преждевременная отслойка нормально расположенной плаценты - 2 (5,7\%), острая гипоксия плода $-4(11,4 \%)$, несвоевременное излитие околоплодных вод - 14 (40,6\%). В экстренном порядке в родах прооперированы 7 (20,3\%) пациенток, из них 5 - с умеренной преэклампсией по показаниям: дискоординация родовой деятельности у 1 (2,9\%), преждевременная отслойка нормально расположенной плаценты - у 1 (2,9\%), упорная слабость родовых сил - у 1 (2,9\%), угрожающая асфиксия плода - у 2 (5,7\%). У 2 пациенток с тяжелой преэклампсией показаниями к операции кесарева сечения во время родов являлись: преждевременная отслойка плаценты - у 1 (2,9\%), угрожающая асфиксия плода - у 1 (2,9\%) пациентки. Из послеродовых осложнений отмечены: гипотоническое кровотечение - у $6(17,1 \%)$ пациенток с тяжелой преэклампсией и $3(8,6 \%)$ пациенток с умеренной преэклампсией; эндометрит - у 4 (11,4\%) пациенток с тяжелой преэклампсией и $6(17,1 \%)$ пациенток с умеренной преэклампсией (табл. 2).

Роды в группе у пациенток с преэклампсией имеют больше осложнений, чем в группе сравнения. Среди осложнений преобладают аномалии сократительной деятельности матки, несвоевременное излитие околоплодных вод, преждевременная отслойка нормально расположенной плаценты, гипоксия плода. Соответственно, выше процент экстренного абдоминального родоразрешения.

При оценке состояния новорожденных у пациенток с преэклампсией установлено: в удовлетворительном состоянии родилось $34,0 \%$ детей. Церебральная ишемия I степени наблюдалась в $37,1 \%$ случаев; церебральная ишемия II степени в 5,7\%; церебральная ишемия III степени - в 5,7\%. Синдром задержки роста плода I степени при преэклампсии отмечался в 17 (49,3\%) случаях, синдром задержки роста плода II степени - в $5(14,5 \%)$, синдром задержки роста плода III степени - в 2 (5,7\%). Синдром гипервозбудимости выявлен у $8(23,2 \%)$, внутрижелудочковые кровоизлияния - у 7 (20,3\%), кефалогематома - у 5 (14,5\%), гипербилирубинемия - у $12(34,8 \%)$, внутриутробная инфекция у $9(26,1 \%)$ новорожденных. 
Таблица 1. Количество примененных местных анестетиков в зависимости от уровня витамина D, эндотелина, мочевой кислоты и концентрации ренина у исследуемых пациенток

Table 1. The amount of consumed local anesthetics depending on the level of vitamin $\mathrm{D}$, endothelin, uric acid, and renin concentration in the examined patients

\begin{tabular}{|c|c|c|c|c|}
\hline \multirow[b]{2}{*}{ Показатели } & \multicolumn{2}{|c|}{ Пациентки с преэклампсией $(n=35)$} & \multirow{2}{*}{$\begin{array}{c}\text { Группа сравнения }(n=30) \\
\text { пациентки с } \\
\text { физиологическим } \\
\text { течением беременности }\end{array}$} & \multirow[b]{2}{*}{$\begin{array}{c}\text { Mann - Whitney } \\
\text { U Test }\end{array}$} \\
\hline & $\begin{array}{l}\text { тяжелая преэклампсия } \\
\qquad(n=12)\end{array}$ & $\begin{array}{l}\text { умеренная преэклампсия } \\
\qquad(n=23)\end{array}$ & & \\
\hline Витамин D, нг/мл & $11,23 \pm 1,60$ & $13,16 \pm 1,40$ & $31,2 \pm 1,7$ & $\begin{aligned} p_{I-I I} & =0,69 \\
p_{1|-| I I} & <0,001 \\
p_{\text {I-III }} & <0,001\end{aligned}$ \\
\hline Эндотелин, 1-38, пмоль/л & $0,12 \pm 0,10$ & $1,01 \pm 0,20$ & $0,05 \pm 0,02$ & $\begin{aligned} p_{1-||} & <0,001 \\
p_{\mid I-I I I} & <0,001 \\
p_{|-| I I} & =0,32\end{aligned}$ \\
\hline Ренин, пг/мл & $41,4 \pm 0,4$ & $61,4 \pm 0,6$ & $5,1 \pm 0,3$ & $\begin{array}{l}p_{1-\mid \mathrm{I}}<0,001 \\
p_{\text {II-III }}<0,001 \\
p_{\text {I-III }}<0,001\end{array}$ \\
\hline Уровень МК, мкмоль/л & $435,61 \pm 24,05$ & $315,52 \pm 17,05$ & $267,00 \pm 32,25$ & $\begin{array}{l}\underline{p}_{1-||}<0,05 \\
p_{\mid I-I I I}<0,05 \\
p_{|-| I I}<0,01\end{array}$ \\
\hline Ропивакаин эпидурально, мг/ч & $30-40$ & 20-30 & $15-20$ & $\begin{array}{l}p_{1-I I}<0,05 \\
p_{1 \mid-I I I}<0,05 \\
p_{1-I I I}<0,01\end{array}$ \\
\hline Левобупивакаин эпидурально, мг/ч & 20-30 & $10-20$ & $5-10$ & $\begin{array}{l}p_{1-I I}<0,05 \\
p_{1|-| I I}<0,05 \\
p_{1-I I I}<0,01\end{array}$ \\
\hline
\end{tabular}

Таблица 2. Течение родов в исследуемых группах

Table 2 . The course of labor in the groups within the study

\begin{tabular}{|c|c|c|c|c|}
\hline \multirow{2}{*}{ Характер осложнений родов } & \multicolumn{2}{|c|}{ Пациентки с преэклампсией $(n=35)$} & \multirow{2}{*}{$\begin{array}{c}\text { Группа сравнения - } \\
\text { пациентки } \\
\text { с физиологическим } \\
\text { течением беременности } \\
(n=30)\end{array}$} & \multirow{2}{*}{$\begin{array}{c}\text { Уровень } \\
\text { значимости } \\
\text { точного критерия } \\
\text { Фишера }\end{array}$} \\
\hline & $\begin{array}{l}\text { тяжелая преэклампсия } \\
\qquad(n=12)\end{array}$ & $\begin{array}{l}\text { умеренная преэклампсия } \\
\qquad(n=23)\end{array}$ & & \\
\hline Оперативные роды & $6(17,1 \%)$ & $5(14,3 \%)$ & $3(10,0 \%)$ & $\begin{array}{l}p_{\text {I-II }}>0,05 \\
p_{\text {II-III }}>0,05 \\
p_{\text {I-III }}<0,05\end{array}$ \\
\hline - плановые & 0 & 0 & $1(3,3 \%)$ & $\begin{array}{l}p_{\text {I-II }}>0,05 \\
p_{\text {II-III }}>0,05 \\
p_{\text {I-III }}>0,05\end{array}$ \\
\hline $\begin{array}{l}\text { - экстренные (во время } \\
\text { беременности) }\end{array}$ & $4(11,4 \%)$ & 0 & $2(6,7 \%)$ & $\begin{array}{l}p_{1-I I}<0,05 \\
p_{I I-I I I}>0,05 \\
p_{1-I I I}<0,05\end{array}$ \\
\hline - экстренные (во время родов) & $2(5,7 \%)$ & $5(14,3 \%)$ & 0 & $\begin{array}{l}p_{1-I I}>0,05 \\
p_{I I-I I I}<0,05 \\
p_{1-I I I}>0,05\end{array}$ \\
\hline Самопроизвольные роды & $6(17,1 \%)$ & $18(51,4 \%)$ & $27(90,0 \%)$ & $\begin{array}{l}p_{\text {I-II }}>0,05 \\
p_{\text {II-III }}>0,05 \\
p_{\text {I-III }}<0,05\end{array}$ \\
\hline Слабость родовой деятельности & $2(5,7 \%)$ & $5(14,3 \%)$ & $4(13,3 \%)$ & $\begin{array}{l}p_{\text {I-II }}>0,05 \\
p_{I I-I I I}>0,05 \\
p_{\text {I-III }}>0,05\end{array}$ \\
\hline $\begin{array}{l}\text { Дискоординация родовой } \\
\text { деятельности }\end{array}$ & 0 & $1(2,9 \%)$ & 0 & $\begin{array}{l}p_{1-I I}>0,05 \\
p_{I I-I I I}>0,05 \\
p_{1-I I I}>0,05\end{array}$ \\
\hline Острая гипоксия плода & $2(5,7 \%)$ & $2(5,7 \%)$ & $1(3,3 \%)$ & $\begin{array}{l}p_{\text {I-II }}>0,05 \\
p_{\text {II-III }}>0,05 \\
p_{\text {I-III }}>0,01\end{array}$ \\
\hline $\begin{array}{l}\text { Преждевременная отслойка } \\
\text { нормально расположенной паценты }\end{array}$ & $1(2,9 \%)$ & $1(2,9 \%)$ & 0 & $\begin{array}{l}p_{1-\mid I}>0,05 \\
p_{1|-| I I}>0,05 \\
p_{1-\mid I I}>0,05\end{array}$ \\
\hline $\begin{array}{l}\text { Несвоевременное излитие } \\
\text { околоплодных вод }\end{array}$ & $3(8,6 \%)$ & $11(31,4 \%)$ & $1(3,3 \%)$ & $\begin{array}{l}p_{1-I I}>0,05 \\
p_{1|-| I I}<0,05 \\
p_{1-\mid I I}>0,05\end{array}$ \\
\hline
\end{tabular}


В группе сравнения в удовлетворительном состоянии родились $23(76,7 \%)$ новорожденных, в состоянии церебральной ишемии I степени - 7 (23,3\%), церебральной ишемии II и III степеней не отмечалось. У новорожденных группы сравнения выявлены: синдром задержки роста плода I степени - в 2 (6,7\%) случаях, синдром гипервозбудимости - в $4(13,3 \%)$, кожногеморрагический синдром - в 1 (3,3\%), кефалогематома - в 1 (3,3\%), внутрижелудочковые кровоизлияния - в $1(3,3 \%)$, гипербилирубинемия в $-2(6,7 \%)$ случаях (табл. 3$)$.

Сравнительный анализ состояния новорожденных обнаружил, что у новорожденных, матери которых страдали преэклампсией, церебральная ишемия наблюдалась в 2,2 раза чаще, чем в группе сравнения.

\section{Обсуждение результатов}

У женщин с преэклампсией наблюдали высокий процент неблагоприятных перинатальных исходов, у новорожденных церебральная ишемия имела место в 2,2 раза чаще, чем в группе сравнения. В связи с этим необходимо проводить профилактические мероприятия, направленные на снижение уровня перинатальных осложнений у новорожденных, патологических проявлений в раннем и позднем неонатальном периоде, что, конечно, влияет на уровень заболеваемости и смертности новорожденных в период младенчества.

Дефицит витамина D является фактором риска развития преэклампсии, повышенные содержание эндотелина и концентрация ренина в сыворотке крови обусловливают повышение АД, а повышение уровня мочевой кислоты является предиктором тяжести течения преэклампсии [11].

В результате исследования выявлено, что более низкие уровни витамина D связаны с более высо- кой потребностью введения эпидурально местных анестетиков при анальгезии родов. Этот вывод согласуется с результатами ранее проведенных исследований, ассоциирующих гиповитаминоз D с болью. Считается, что витамин D активирует нисходящие модулирующее пути, ингибирующие боль [6, 11].

Механизмы, лежащие в основе ассоциации между гиповитаминозом $\mathrm{D}$ и восприятием боли во время и после родов, потенциально являются основанием для дальнейшего исследования. Учитывая высокую распространенность дефицита и недостаточности витамина D у родильниц, эффективная профилактика и лечение могут иметь значительное влияние на снижение родовой боли у миллионов женщин. Рекомендации по выбору дозы витамина D во время беременности, возможно, должны быть пересмотрены.

Таким образом, можно заключить, что физиологический уровень витамина $\mathrm{D}$ способствует благоприятному течению беременности и родов. При проведении эпидуральной анальгезии обнаружено, что пациенткам с преэклампсией с низким уровнем витамина D и повышенной концентрацией мочевой кислоты для уменьшения боли и стабилизации АД необходимо большее удельное количество вводимого местного анестетика, чем пациенткам с более высоким уровнем витамина D.

Очевидна необходимость коррекции дефицита витамина D по времени назначения и подбора дозы препаратов витамина $\mathrm{D}$ в зависимости от исходного уровня и особенностей организма [7]. По существующим представлениям, для предупреждения осложнений, связанных с дефицитом витамина D при беременности, необходимо поддержание уровня 25(OH)D более 30 нг/мл.

Пациенткам группы высокого риска развития преэклампсии во время беременности необходимо

Таблица 3. Осложнения у новорожденных пациенток групп исследования

Table 3. Complications in newborns of the patients in the groups within the study

\begin{tabular}{|c|c|c|c|}
\hline $\begin{array}{l}\text { Характер осложнений } \\
\text { у новорожденных }\end{array}$ & $\begin{array}{c}\text { Основная группа - пациентки } \\
\text { с преэклампсией }(n=35)\end{array}$ & $\begin{array}{c}\text { Группа сравнения - } \\
\text { пациентки с физиологическим } \\
\text { течением беременности }(n=30)\end{array}$ & $\begin{array}{c}\text { Уровень значимости точного } \\
\text { критерия Фишера }\end{array}$ \\
\hline $\begin{array}{l}\text { Церебральная ишемия } \\
\text { І степени } \\
\text { II степени } \\
\text { III степени }\end{array}$ & $\begin{array}{c}13(37,1 \%) \\
5(14,5 \%) \\
2(5,7 \%)\end{array}$ & $\begin{array}{c}7(23,3 \%) \\
0 \\
0\end{array}$ & $\begin{array}{l}p>0,05 \\
p>0,05 \\
p>0,05\end{array}$ \\
\hline $\begin{array}{l}\text { Синдром задержки развития плода } \\
\text { І степени } \\
\text { II степени } \\
\text { III степени }\end{array}$ & $\begin{array}{c}17(49,3 \%) \\
5(14,5 \%) \\
2(5,7 \%)\end{array}$ & $\begin{array}{c}2(6,7 \%) \\
0 \\
0\end{array}$ & $\begin{array}{l}p<0,05 \\
p>0,05 \\
p>0,05\end{array}$ \\
\hline Синдром гипервозбудимости & $8(23,2 \%)$ & $4(13,3 \%)$ & $p>0,05$ \\
\hline Внутрижелудочковые кровоизлияния & $7(20,3 \%)$ & $1(3,3 \%)$ & $p>0,05$ \\
\hline Судорожный синдром & $4(11,4 \%)$ & 0 & $p>0,05$ \\
\hline Кефалогематома & $5(14,5 \%)$ & 0 & $p>0,05$ \\
\hline Кожногеморагический синдром & $6(17,1 \%)$ & $1(3,3 \%)$ & $p>0,05$ \\
\hline Гипербилирубинемия & $12(34,8 \%)$ & $5(16,6 \%)$ & $p>0,05$ \\
\hline Внутриутробная инфекция & $9(26,1 \%)$ & $2(6,7 \%)$ & $p>0,05$ \\
\hline
\end{tabular}


определение уровня мочевой кислоты в сыворотке крови как одного из маркеров преэклампсии.

\section{Выводы}

У пациенток с преэклампсией выявлены: низкий уровень витамина D, гиперурикемия, повышенная концентрация ренина в крови, что прямо ассоциировано с выраженностью болевого синдрома и повышением АД. Возможно, восполнение дефицита витамина D во время беременности улучшит перинатальные исходы.

Роженицы с преэклампсией на фоне низкого уровня витамина D, гиперурикемии и с повышенным содержанием ренина и эндотелина в крови для адекватной анальгезии и контроля АД в родах, возможно, нуждаются в более высокой скорости введения местных анестетиков, чем беременные с референсными значениями исследуемых параметров.

Конфликт интересов. Авторы заявляют об отсутствии у них конфликта интересов.

Conflict of Interests. The authors state that they have no conflict of interests.

\section{ЛИТЕРАТУРА}

1. Акушерство / под ред. В. Е. Радзинского, А. М. Фукса. М.: ГЭОТАР- Медиа, 2016. -1040 c.

2. Акушерство: национальное руководство / под ред. В. И. Кулакова, Э. К. Айламазян, В. Е. Радзинского. - М.: ГЭОТАР-Медиа, 2008. - 1200 с.

3. Клинические рекомендации (протокол лечения). Министерство здравоохранения Российской Федерации: письмо от 7 июня 2016 г. № 15-4/10/2 3483 «Гипертензивные расстройства во время беременности, в родах и послеродовом периоде. Преэклампсия. Эклампсия».

4. Кузнецова Л. В., Хаджиева Э. Д., Зазерская И. Е. Уровень обеспеченности витамином D беременных с преэклампсией // Артериальная гипертензия. - 2015. - Т. 21, № 6. - С. 623-629.

5. Мальцева Л. И., Васильева Э. Н., Денисова Т. Г. Витамин D и преэклампсия // Российский вестник акушера-гинеколога. - 2016. - Т. 16, № $1 .-$ C. $79-83$.

6. Мальцева Л. И., Васильева Э. Н., Денисова Т. Г. Значение дефицита витамина D для развития тяжелых форм преэклампсии у женщин группы высокого риска // Акушерство и гинекология. - 2018. - № 9. - С. 120-125.

7. Совещание координаторов по вопросам охраны здоровья женщин и детей: отчет о совещании ВОЗ. - Женева: ЕРБ ВОЗ, 2015. - 22 с.

8. Arriagada G., Paredes R., van Wijnen A. J. et al. 1alpha,25-dihydroxy vitamin $\mathrm{D}(3)$ induces nuclear matrix association of the 1alpha,25-dihydroxy vitamin $\mathrm{D}$ (3) receptor in osteoblasts independently of its ability to bind DNA // J. Cell. Physiol. - 2010. - Vol. 222. - P. 336-346.

9. Bodnar L. M., Klebanoff M. A., Gernand A. D. et al. Maternal vitamin D status and spontaneous preterm birth by placental histology in the US Collaborative Perinatal Project // Am. J. Epidemiol. - 2014. - Vol. 179, № 2. - P. 168-176.

10. Cnossen J. S. Accuracy of serum uric acid determination in predicting pre-eclampsia // Acta Obstet. Gynecol. Scand. - 2006. - Vol. 85, № 5. P. 519-525.

11. Deruelle P., Coudoux E., Ego A. et al. Risk factors for post-partum complications occurring after preeclampsia and HELLP syndrome. A study in 453 consecutive pregnancies // Eur. J. Obstet. Gynecol. Reprod. Biol. - 2006. - Vol. 125, № 1. P. 59-65.

12. Haugen M., Brantsaeter A. L., Trogstad L. et al. Vitamin D supplementation and reduced risk of preeclampsia in nulliparous women // Epidemiology. 2009. - Vol. 20, № 5. - P. 720-726.

13. Holick M. F. Vitamin D deficiency // New Engl. J. Med. - 2007. - Vol. 357. P. 266-281.

14. Parlak M., Kalay S., Kalay Z. et al. Severe vitamin D deficiency among pregnant women and their newborns in Turkey // J. Matern. Fetal. Neonatal. Med. 2015. - Vol. 28, № 5. - P. 548-551.

15. Powers R.W. Uric acid concentrations in early pregnancy among pre-eclamptic women with gestational hyperuricemia at delivery // Am. J. Obstet. Gynecol. 2006. - Vol. 1. - P. 160

16. Roberts J. M. Bodnar L. M., Lain K. Y. et al. Uric acid is as importan as proteinuria in identifying fetal risk in women with gestational hypertension // Hypertension. - 2005. - Vol. 46, № 6. - P. 1263-1269.

\section{REFERENCES}

1. Akusherstvo. [Obstetrics]. V.E. Radzinskiy, A.M. Fuks, eds., Moscow, GEOTAR-Media Publ., 2016, 1040 p.

2. Akusherstvo. Natsionalnoye rukovodstvo. [Obstetrics. National guidelines]. V.I. Kulakov, E.K. Aylamazyan, V.E. Radzinskiy, eds. Moscow, GEOTAR-Media Publ., 2008, 1200 p.

3. Clinical recommendations (treatment protocol). Ministry of Health of the Russian Federation: Letter No. 15-4/10/2-3483 dated June 7, 2016, by the Russian Ministry of Health On Hypertensive Disorders During Pregnancy, in Labor and in Postpartum Period. Pre-eclampsia. Eclampsia. (In Russ.)

4. Kuznetsova L.V., Khadzhieva E.D., Zazerskaya I.E. The level of vitamin D in pregnant women with pre-eclampsia. Arterialnaya Gipertenziya, 2015, vol. 21, no. 6, pp. 623-629. (In Russ.)

5. Maltseva L.I., Vasilieva E.N., Denisova T.G. Vitamin D and pre-eclampsia. Rossiysky Vestnik Akushera-Ginekologa, 2016, vol. 16, no. 1, pp. 79-83. (In Russ.)

6. Maltseva L.I., Vasilieva E.N., Denisova T.G. The importance of vitamin D deficiency for the development of severe pre-eclampsia in women from high risk groups. Akusherstvo i Ginekologiya, 2018, no. 9, pp. 120-125. (In Russ.)

7. Coordinating meeting on maternal and child health: WHO meeting report. Geneva, Regional Office for Europe, WHO, 2015, 22 p. (In Russ.)

8. Arriagada G., Paredes R., van Wijnen A.J. et al. 1alpha,25-dihydroxy vitamin $\mathrm{D}(3)$ induces nuclear matrix association of the 1alpha,25-dihydroxy vitamin $\mathrm{D}$ (3) receptor in osteoblasts independently of its ability to bind DNA. J. Cell. Physiol., 2010, vol. 222, pp. 336-346.

9. Bodnar L.M., Klebanoff M.A., Gernand A.D. et al. Maternal vitamin D status and spontaneous preterm birth by placental histology in the US Collaborative Perinatal Project. Am. J. Epidemiol., 2014, vol. 179, no. 2, pp. 168-176.

10. Cnossen J.S. Accuracy of serum uric acid determination in predicting pre-eclampsia. Acta Obstet. Gynecol. Scand., 2006, vol. 85, no. 5, pp. 519-525.

11. Deruelle P., Coudoux E., Ego A. et al. Risk factors for post-partum complications occurring after preeclampsia and HELLP syndrome. A study in 453 consecutive pregnancies. Eur. J. Obstet. Gynecol. Reprod. Biol., 2006, vol. 125 , no. 1 , pp. 59-65.

12. Haugen M., Brantsaeter A.L., Trogstad L. et al. Vitamin D supplementation and reduced risk of preeclampsia in nulliparous women. Epidemiology, 2009, vol. 20 , no. 5 , pp. $720-726$.

13. Holick M.F. Vitamin D deficiency. New Engl. J. Med., 2007, vol. 357, pp. 266-281.

14. Parlak M., Kalay S., Kalay Z. et al. Severe vitamin D deficiency among pregnan women and their newborns in Turkey. J. Matern. Fetal. Neonatal. Med., 2015, vol. 28 , no. 5 , pp. 548-551.

15. Powers R.W. Uric acid concentrations in early pregnancy among pre-eclamptic women with gestational hyperuricemia at delivery. Am. J. Obstet. Gynecol., 2006, vol. 1, pp. 160.

16. Roberts J.M., Bodnar L.M., Lain K.Y. et al. Uric acid is as important as proteinuria in identifying fetal risk in women with gestational hypertension. Hypertension, 2005 , vol. 46 , no. 6 , pp. $1263-1269$ 
17. Thangaratinam S., Ismail K. M., Sharp S. et al. Accuracy of serum uric acid in predicting complications of pre-eclampsia // Brit. J. Obstet. Gynecol. - 2006. Vol. 113, № 4. - P. 369-378.

18. Thorne-Lyman A., Fawzi W. W. Vitamin D during pregnancy and maternal, neonatal and infant health outcomes: a systematic review and meta-analysis // Pediatr. Perinat. Epidemiol. - 2012. - Vol. 26 (Suppl. 1). - P. 75-90.

\section{ДЛЯ КОРРЕСПОНДЕНЦИИ:}

ГАУ ДПО «Институт усовершенствования врачей» Минздрава Чувашии,

428000, г. Чебоксары, ул. М. Сеспеля, д. 27.

\section{Орешников Евгений Витальевич}

кандидат медицинских наук.

E-mail:ev_oreshnikov@mail.ru

\section{Васильева Эльвира Николаевна}

доцент кафедры акушерства и гинекологии.

E-mail:elnikvas@mail.ru

\section{Денисова Тамара Геннадъевна}

проректор по научной работе и информатизаиии.

E-mail: tomadenisova@rambler.ru

\section{Мальцева Лариса Ивановна}

Казанская государственная медицинская академия филиал ФГБОУ ДПО «Российская медииинская академия непрерывного профессионального образования» МЗ РФ, профессор кафедры акушерства и гинекологии. 420012, г. Казань, ул. Муштари, д. 11

E-mail:laramalc@mail.ru
17. Thangaratinam S., Ismail K.M., Sharp S, et al. Accuracy of serum uric acid in predicting complications of pre-eclampsia. Brit. J. Obstet. Gynecol., 2006, vol. 113 , no. 4 , pp. 369-378.

18. Thorne-Lyman A., Fawzi W.W. Vitamin D during pregnancy and maternal, neonatal and infant health outcomes: a systematic review and meta-analysis. Pediatr. Perinat. Epidemiol., 2012, vol. 26, suppl. 1, pp. 75-90.

\section{FOR CORRESPONDENCE:}

Institute of Continuing Medical Education,

27, M. Sespel St.

Cheboksary, 428000

\section{Evgeniy V. Oreshnikov}

Candidate of Medical Sciences.

Email:ev_oreshnikov@mail.ru

\section{Elvira N. Vasilieva}

Associate Professor of Obstetrics and Gynecology Department.

Email:elnikvas@mail.ru

Tamara G. Denisova

Vice Rector for Research and Information Technology.

Email:tomadenisova@rambler.ru

\section{Larisa I. Maltseva}

Kazan State Medical Academy -

Branch of Russian Medical Academy of Continuing

Professional Education,

Professor of Obstetrics and Gynecology Department.

11, Mushtari St., Kazan, 420012

Email:laramalc@mail.ru 